\title{
Meeting the Claims of Psychodermatologic Research and Clinical Practice
}

We have started the fifth year of DeRmatology+PsychosoMATICS with the intention to be part of a process that includes psychological issues into a broad diversity of dermatologic issues and to present a number of articles that may be integrated into the readers' clinical practice or research activities. During the past five years of establishing and shaping the journal's profile we have found more and more ways to meet practitioners' interests and stick to a scientific approach to psychosomatic dermatology. To this end, we introduced the section 'For the Practitioner' that reflects clinicians' experiences under their individual conditions and in their respective cultural context. Another section established to serve the requirements of clinicians is the 'Education' that summarizes clinical and psychosomatic issues of selected dermatologic diseases, such as Urticaria [Raap et al., 2004], balanced to clinical practice.

Nevertheless, we have not failed to present a variety of scientific issues of interest and relevance for psychodermatologic therapy and research, including neurobiologic issues, endocrinologic topics and articles dealing with coping aspects in dermatoses as well as the more traditional subject of personality aspects in patients with psychodermatologic conditions. These different perspectives illuminate a broad spectrum of dermatoses including common skin diseases such as psoriasis and atopic dermatitis and less frequent dermatoses such as glossodynia, delusional parasitosis, plantar petechiae, etc.

The present issue completes the fifth volume of the journal, and presents once again various psychodermatologic topics relevant for clinical practice and research: The original article by Papadopoulus et al. [2004] deals with coping aspects in patients with vitiligo and reflects the disfiguring aspect of the disease that has to be understood in its cultural context with a particularly pronounced psychosocial impact in Mediterranean countries. By comparing cognitive-behavioral therapy and person-centered therapy the effects of psychotherapeutic approaches on vitiligo patients can be better understood. Schmid-Ott and colleagues [2004] focus on coping aspects in patients with psoriasis and emphasize the relevance of the severity of the disease for the patients' need for psychosocial support. The experiences with a combined educational and medical program for children with atopic dermatitis and their parents [Ricci et al., 2004] support results of investigations on psychotherapeutic interventions in the present issue. The results achieved are encouraging because they show that the families' quality of life improved during participation in the program.

In the present issue of Dermatology+Psychosomatics, delusional parasitosis is dealt with in two case reports by a Polish author group [Pacan et al., 2004] and in an original article on the use of pimozide in that disorder [Lee and Koo, 2004]. Delusional parasitosis as a psychotic disorder represents in clinical terms a field in which close cooperation between psychiatry and dermatology is essential. Finally, a rather essayistic contribution on skin and intimacy [Kutter, 2004] rounds off the present issue.

We wish all our readers a pleasant and beneficial reading! Ina Zschocke, Freiburg i.Br.

\section{References}

Kutter P: Skin and intimacy - psychoanalytic reflections. Dermatol Psychosom 2004;5:196-202.

Lee M, Koo J: Pimozide: The opiate antagonist hypothesis and use in delusions of parasitosis. Dermatol Psychosom 2004;5:184-186.

Pacan P, Reich A, Szepietowski JC: Delusional parasitosis successfully controlled with risperidone - two case reports. Dermatol Psychosom 2004;5:193-195

Papadopoulos L, Walker C, Anthis L: Living with vitiligo: A controlled investigation into the effects of group cognitive-behavioural and person-centred therapies. Dermatol Psychosom 2004;5:172-177.

Raap U, Gieler U, Schmid-Ott G: Urticaria. Dermatol Psychosom 2004;5:203-205.

Schmid-Ott G, Hofste N, Niederauer H-H, Lamprecht F, Künsebeck H-W: Illness severity and coping in psoriasis patients: A 1-year follow-up. Dermatol Psychosom 2004;5:178-183.

\begin{tabular}{ll}
\hline KARGER & @ 2004 S. Karger GmbH, Freiburg \\
Fax +49 7614 52 07 14 & Accessible online at: \\
$\begin{array}{l}\text { E-mail Information@Karger.de } \\
\text { www.karger.com }\end{array}$ & www.karger.com/dps
\end{tabular}

Dr. Ina Zschocke

ICAMmed $\mathrm{GmbH}$ - Institute for

Clinical Molecularbiological Research

Wilhelmstr. 5, D-79098 Freiburg

Tel. +49 761 45754-11, Fax 45754-29

E-mail zschocke@ifks-biometrie.de 